Proceedings

\title{
A First Insight Into the Occurrence of Cockroaches in the Urban City of Thessaloniki (Greece) - Identifying Hot Spots ${ }^{+}$
}

\author{
Ioanna Dimitriadou ${ }^{1,}{ }^{*}$, Georgios I. Memtsas ${ }^{2}$, Fotis Xystrakis ${ }^{3}$, Dimitrios Kavvadas ${ }^{1}$, Theodora Papamitsou ${ }^{1}$ and \\ Dimitrios N. Avtzis ${ }^{3}$
}

Citation: Dimitriadou, I.; Memtsas, G.; Xystrakis, F.; Kavvadas, D.; Papamitsou, T. and Avtzis, D.N. A First Insight into the Occurrence of Cockroaches in the Urban City of Thessaloniki (Greece)-Identifying Hot Spots, in Proceedings of the 1st International Electronic Conference on Entomology, 1-15 July 2021, MDPI: Basel, Switzerland, doi:10.3390/IECE-10682

Published: 15 July 2021

Publisher's Note: MDPI stays neutral with regard to jurisdictional claims in published maps and institutional affiliations.

Copyright: (c) 2021 by the authors. Submitted for possible open access publication under the terms and conditions of the Creative Commons Attribution (CC BY) license (http://creativecommons.org/licenses /by/4.0/).
1 Aristotle University of Thessaloniki, School of Medicine, Thessaloniki, Greece.

2 Aristotle University of Thessaloniki, School of Biology, Thessaloniki, Greece.

3 Forest Research Institute, Hellenic Agricultural Organization Demeter, Vassilika, Thessaloniki, Greece.

* Correspondence: iodimi93@gmail.com

† Presented at the 1st International Electronic Conference on Entomology (IECE 2021), 1-15 July 2021; Available online: https://iece.sciforum.net/.

\begin{abstract}
Blattodea is one of the most common orders particularly in urban centers. The most abundant species in Greece are Blatta orientalis and Periplaneta americana (Blattidae), Blattella germanica and Supella longipalpa (Blattelidae). They are cosmopolitan species occurring in homes, restaurants, hotels, hospitals, offices and libraries. They are omnivores, feeding on a variety of food resources, ranging from manure and feces to organic waste. They prefer dark and humid sites and pose a significant threat for public health as their occurrence is often associated with asthma and allergic rhinitis. As a consequence, mapping of cockroaches' hot spots in urban areas is a prerequisite for any effective control program. Despite their significance, very little is known regarding the occurrence and distribution of cockroaches in the city of Thessaloniki (Macedonia). The aim of this preliminary study is the spatial mapping of the places where health services carried out disinfestations for cockroaches, in order to identify places with an increased presence of these pests.
\end{abstract}

Keywords: Urban entomology; Distribution; Cockroaches; Blattodea; Allergens

\section{Introduction}

Cockroaches are hemimetabolan insects which belong in the order of Blattodea. They can be divided into five families : Cryptocercidae, Polyphagidae, Blattidae, Blattellidae and Bladeridae [1]. The majority of cockroaches fall into the latter three families [2] with a length that may range from 2 to $100 \mathrm{~mm}$ [3]. A typical cockroach body is flattened and broadly oval with a large shield-like pronotum which serves as a valuable systematic character for certain groups. Their body also includes chewing mouthparts, ventrally deployed and long, highly segmented antennae; 150-170 segments in a typical antennal scanning [4]. In the context of dimorphism, female and male cockroaches may have differences in the color and shape of the body or in the size, color and shape of specific body parts [2]. Cockroaches are nocturnal and omnivorous species [5]. They feed in a wide range of food substances, greater than any other insect [6]. Environmental factors such as spatial distribution, persistence of food sources and also associative learning and cognitive capacities are significant criteria on the choice of foraging tactics in cockroaches [7].

Due to their living and feeding habits, cockroaches are ideal vectors of pathogens [5]. Numerous pathogens have been isolated on the exterior of the body of Blattella germanica ranging from bacteria (Bacillus spp., Staphylococcus spp., Escherichia coli, Pseudomonas spp., Enterobacta spp., Klebsiella spp., Erwinia spp., Salmonella sp., Shigella sp. and Serratia spp.), and yeasts (Pichia sp., Candida sp. and Torulopsis spp.) to common moulds (Aspergillus flavus, Aspergillus fumigatus and Aspergillus parasiticus). Many of these pathogens are responsible for food spoilage constituting significant threats to food safety [8]. Additionally, the occurrence of cockroaches is often associated with the development of asthma and allergic 
rhinitis [9]. The two most abundant species, B. germanica and Periplaneta americana, produce a number of potent allergens, such as Bla g 2, Bla g 4, Bla g 5, group 1 of the crossreactive allergens Bla $\mathrm{g} 1$ and Per a 1, tropomyosin [10] and the allergen alpha-amylase 53 kDA [11]. In general, cockroaches are an important source of indoor allergens can lead to IgE sensitization, the development of allergic rhinitis and asthma [12].

Despite the significance of cockroaches, little is known about their presence and distribution in Greece. Based on one of the few related studies, cockroaches were found to be the second most abundant pest in ferries arriving to and departing from the Port of Piraeus (11/21 ferries) [13]. In addition, a study which took place in sixteen hospitals in Athens, showed that individuals of B. germanica and P. americana were reported in two hospitals, with the pest control companies suggesting that for half the hospitals it their construction that favors the emergence and survival of these pests [14]. However, the distribution pattern of cockroaches within an urban area has never been investigated before, an issue that is investigated in the current study. Using the city of Thessaloniki (Macedonia) as a case study, we targeted at mapping the distribution of cockroaches' infestations within an urban area, and then relate the hot-spots revealed with urban structures and constructions.

\section{Materials and Methods}

Occurrence data of cockroach infestation were provided by two pest control companies that are active in the city of Thessaloniki. In total, 283 locations were used, corresponding to places where these companies performed a chemical treatment against cockroaches in 2019-2020. Based on the behavior of cockroaches, a radius of $500 \mathrm{~m}$ around each location was employed when constructing the density map using QGis Version 3.18.3 [15]. In this density map, three classes were implemented, namely up to 2 recordings, 2-7 recordings, and more than 7 recordings.

\section{Results}

The spatial mapping of the locations clearly (Figure 1) showed an extensive area east of the center but also smaller scattered locations in areas west of the center, where the occurrence density of cockroaches is particularly strong. Intense cockroach infestations were observed in areas around the city hospitals. Also, significant but less intense infestations were recorded in areas with dense construction and old buildings. 


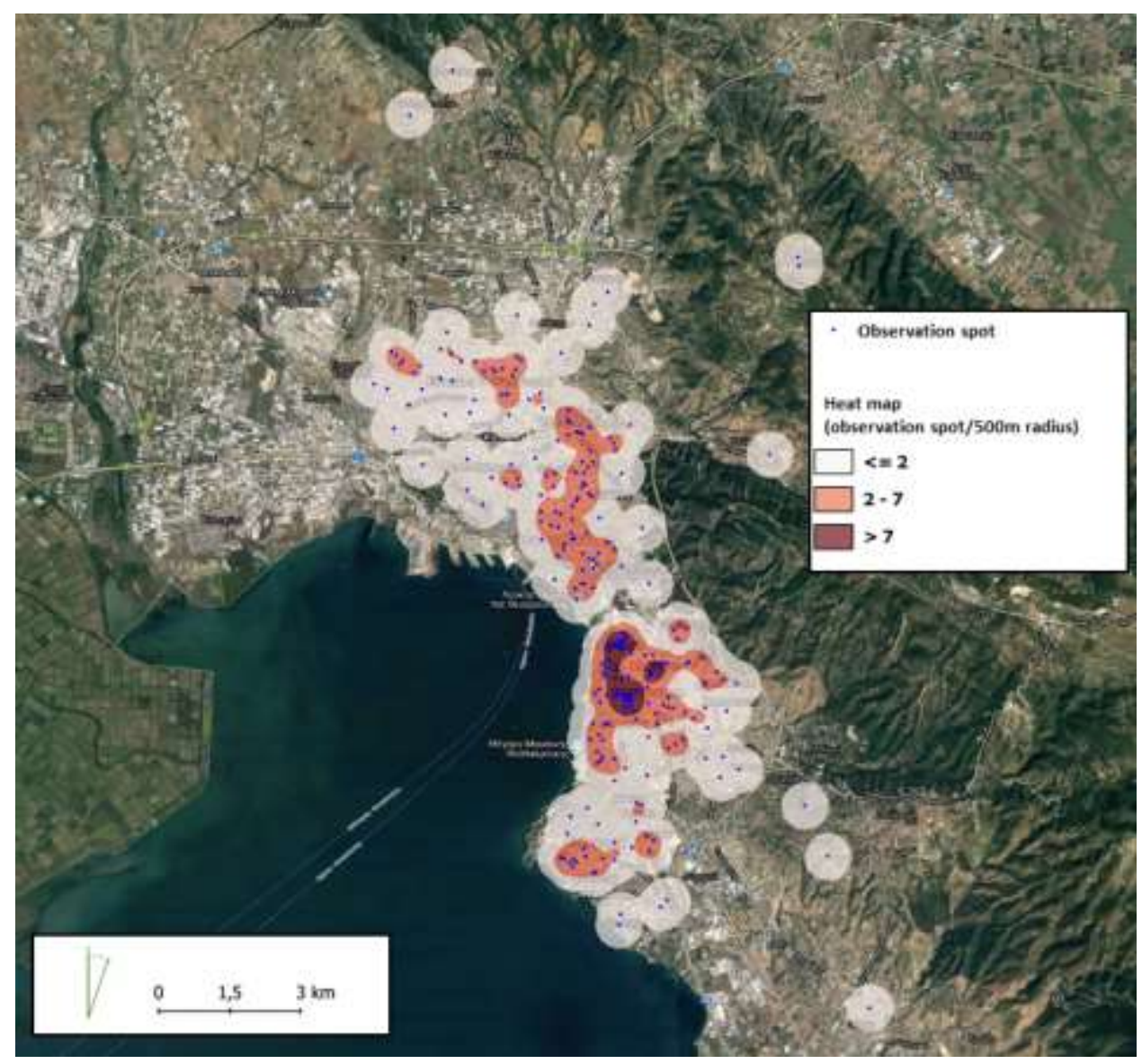

Figure 1. Heat map showing the observation spots of Blattodea in Thessaloniki.

\section{Discussion}

The mapping of these preliminary distribution data has clearly shown that the areas of high density of cockroaches are located near Hospital facilities. This fact concerns the extensive area of the city center. Similar studies, have demonstrated that cockroaches is often common pest inside hospital facilities [16,17]. In Tikur Anbessa Hospital, Addis Ababa, a total of 400 cockroaches were collected from neonatal intensive care unit. Findings showed that the bacterial pathogens which isolated from cockroaches' bodies and guts are responsible for neonatal nosocomial sepsis [16]. The hospitals' internal conditions such as temperature, humidity, food and ample harbourage seem to create an ideal environment for cockroaches' infestations [17].

Furthermore, areas with high cockroach density are found within very densely populated and old parts of city. In an urban network there are many parameters which contribute to the high percentage of apartments with cockroach infestations. Some of them are poor sanitation and pest control practices, lack of proper maintenance of the apartments and natural dispersal of cockroaches between apartments within multi-unit dwellings [18]. Additionally, socioeconomic status plays an important role in cockroaches' treatment $[19,20,21,22]$. Peers living in an urban environment and experience high levels of material hardship show a positive correlation with an increase in exposure in cockroach allergens [19]. Also, factors such as substandard housing and multiunit buildings are thought to provide cockroach infestation [20], while two large studies [21,22] took place in the United States confirmed that low family income and living in a multifamily home into a high population density area with a higher occupancy rate per room associated with increased cockroach allergens and low concentrations of dust mite, cat and dog allergens.

Being a serious enemy of public health, cockroach populations need monitoring in order to record their distribution within a synchronous urban city. This study will form 
the basis for a more enhanced effort of recording spots which constitute cockroaches' infestations in Thessaloniki. As these species are vectors of serious pathogens $[5,8,16]$ and responsible for IgE sensitization, asthma and allergic rhinitis $[9,12]$ their recording can also contribute to the development of a more effective method of control (Integrated Pest Management) than traditional one which involves the use of pesticides [23].

\section{References}

1. Cochran, D.G.; Encyclopedia of Insects (Second Edition); Vincent H. Resh and Ring T. Cardé, 2009,p. 108-112.

2. Bell, W.J.; Roth, L.M.; Nalepa, C.A.; Cockroaches: Ecology, Behavior and Natural History; The Johns Hopkins University Press, Baltimore, 2007,pp. xiii,1-2.

3. Roth, L.M. Systematics and phylogeny of cockroaches (Dictyoptera: Blattaria). Oriental Insects, 2003,37,1-186.

4. Okada, J.; Kanamaru, Y.; Toh, Y.; Mechanosensory Control of Antennal Movement by the Scapal Hair Plate in the American Cockroach. Zoological Science, 2002,19(11),1201-1210.

5. Etim, S.E.; Okon, O.E.; Akpan, P.A.; Ukpong, G.I.; Oky, E.E. Prevalence of cockroaches (Periplaneta americana) in households in Calabar: Public health implications. Journal of Public Health and Epidemiology, 2013,5,149-152.

6. Lauprasert, P.; Sitthicharoenchai, D.; Thirakhupt, K.; Pradatsudarasar, A. Food Preference and Feeding Behavior of the German Cockroach, Blattela germanica (Linnaeus). J. Sci. Res. Chula. Univ, 2006,31,121-126.

7. Durier, V.; Rivault, C. Effects of spatial knowledge and feeding experience on foraging choices in German cockroaches. The Association for the Study of Animal Behaviour, 2001,62,681-688.

8. Mpuchane, S.; Allotey, J.; Matsheka, I.; Simpanya, M.; Coetzee, S.; Jordan, A.; Mrema, N.; Gashe, B.A. Carriage of micro-organisms by domestic cockroaches and implications on food safety. International Journal of Tropical Insect Science, 2006,26,166-175.

9. Wang, J.; Zhang, Y.; Li, B.; Zhao, Z.; Huang, C.; Zhang, X.; Deng, Q.; Lu, C.; Qian, H.; Yang, X.; Sun, Y.; Sundell, J.; Norbäck, D. Asthma and allergic rhinitis among young parents in China in relation to outdoor air pollution, climate and home environment. Science of the Total Environment, 2021, 751,1-9.

10. Arruda, L.K.; Vailes, L.D.; Ferriani, V.P.; Santos, A.B.; Pomés, A.; Chapman, M.B. Cockroaches allergens and asthma. J Allergy Clin Immunol, 2001,107, 419-428.

11. Ahmandi, F.; Dorosti, H.; Ghasemi, Y.; Nezafat, N. In Silico Design of Epitope-Based Allergy Vaccine Blattella Germanica Cockroaches Allergens. International Journal of Peptide Research and Therapeutics, 2020,26,1739-1749.

12. Stern, J.; Pier, J.; Litonjua, A. Asthma epidemiology and risk factors. Seminars in Immunology, 2020,42,5-15.

13. Mouchtouri, V.A.; Anagnostopoulou R.; Samanidou-Voyadjoglou. A.; Theodoridou, K.; Hatzoglou, C.; Kremastinou, J.; Hadjichristodoulou, C. Surveillance study of vector species on board passenger ships, Risk factors related to infestations. BMC Public Health, 2008,8:100.

14. Nestoridou, K.; Mouchtouri, V.A.; Mavroidi, M.; Zagkalis, Th.; Ntelezos, K. Pest control in 16 hospitals in Greece. Epitheorese Klinikes Farmakologias kai Farmakokinitikes, 2010,28,241-247.

15. QGIS Development Team (2021). QGIS Geographic Information System. Open Source Geospatial Foundation Project. http://qgis.osgeo.org.

16. Tilahum, B.; Worku, B.; Tachbele, E.; Terefe, S.; Kloos, H.; Legesse, W. High load of multi-drug resistant nosocomial neonatal pathogens carried by cockroaches in a neonatal intensive care unit at Tikur Anbessa specialized hospital, Addis Ababa, Ethiopia. Antimicrobial Resistance and Infection Control, 2012,12.

17. Fotedar, R.; Banerjee, U. Nosocomial fungal infections - study of the possible role of cockroaches (Blattella germanica) as vectors. Acta Tropica, 1992,50,339-343.

18. Wang, C.; Eiden, A.; Cooper, R.; Zha, C.; Wang, D.; Reilly, E. Changes in Indoor Insecticide Residue Levels after Adopting an Integrated Pest Management Program to Control German Cockroach Infestations in an Apartment Building. Insects, 2019,10(11), 406 .

19. Koehler, P.G.; Patterson, R.S.; Brewer, R.J.R. German cockroach infestations in low income apartments. Journal of Economic Education, 1987,80,446-450.

20. Brian, P.L.; Belanger, K.; Triche, E.; Holford, T.; Gold, D.R.; Kim, Y.; Jankun, T.; Ren, P.; McSharry, J.; Platts-Mills, T.; Chapman, D.M; Bracken, M. Dust Mite, cockroach, cat and dog allergen concentrations in Homes of Asthmatic Children in the Northeastern United States: Impact of Socioeconomic Factors and Population Density. Environmental Health Perspectives, 2002,110,419-425.

21. Rosenstreich, D.L.; Eggleston, P.; Kattan, M.; Baker, D.; Slavin, R.G; Gergen, P.; Mitchell, H.; McNiff-Mortimer, K.; Lynn, H.; Ownby, D. The role of cockroach allergy and exposure to cockroach allergen in causing morbidity among inner-city children with asthma. The New England Journal of Medicine, 1997,336,1356-1363. 
22. Kitch, B.T.; Chew, G.; Burge, H.A.; Muilenberg, M.L.; Weiss S.T.; Platts-Mills, T.; O' Connor.; Gold, D.R. Socioeconomic Predictors of High Allergen Levels in Homes in the Greater Boston Area. Environmental Health Perspectives, 2000,108,301-307.

23. Kass, D.; McKelvey, W.; Carlton, E.; Hernandez, M.; Chew, G.; Nagle, S.; Garfinkel, R.; Clarke, B.; Tiven, J.; Espino, C.; Evans, D. Effectiveness of an Integrated Pest Management Intervention in Controlling Cockroaches, Mice and Allergens in New York City Public Housing. Environmental Health Perspectives, 2009,117,1219-1225. 